\title{
Estudo retrospectivo de 761 tumores cutâneos em cães
}

\author{
Retrospective study on 761 canine skin tumors
}

\author{
Tatiana Mello de Souza ${ }^{1}$ Rafael Almeida Fighera ${ }^{1}$ \\ Luiz Francisco Irigoyen² Claudio Severo Lombardo de Barros ${ }^{2}$
}

\section{RESUMO}

Os arquivos de biópsias de cães realizadas no Laboratório de Patologia Veterinária da Universidade Federal de Santa Maria entre 1964 e 2003 foram revisados à procura de tumores cutâneos. Dos 703 registros encontrados, em 570 $(81,0 \%)$ estava descrito que o cão apresentava apenas um tumor na pele e, em 133 (19,0\%), que o cão apresentava mais de um tumor. Seiscentos e cinqüenta e quatro $(93,1 \%)$ cães apresentavam apenas um tipo histológico de tumor e 41 (5,8\%) apresentavam dois tumores histologicamente distintos. Em sete $(1,0 \%)$ cães, havia três tumores diferentes e em um $(0,1 \%)$ cão foram diagnosticados quatro tumores não relacionados, finalizando um total de 761 tumores. Dos 761 tumores cutâneos encontrados, $673(88,4 \%)$ eram neoplásicos e $88(11,6 \%)$ eram não-neoplásicos. Os 15 tumores mais prevalentes em ordem decrescente de freqüencia foram: mastocitoma, carcinoma de células escamosas, adenoma perianal, lipoma, tricoblastoma, carcinoma perianal, papiloma, cistos foliculares, hemangioma, hemangiossarcoma, melanoma, adenoma sebáceo, histiocitoma, hiperplasia sebácea nodular e fibroma.

Palavras-chave: doenças de cães, doenças de pele, tumores cutâneos, oncologia, dermatologia, patologia, dermatopatologia.

\section{ABSTRACT}

The biopsy files in dogs from the Veterinary Pathology Laboratory of the Universidade Federal de Santa Maria, RS, Brazil, from 1964 to 2003, were reviewed for skin tumors. In the 703 files, 570 (81.0\%) it was reported that the dog had only one skin tumor and in 133 (19.0\%), more than one tumor was described in the skin. Six hundred and fifty four (93.1\%) dogs had only one histologic type of tumor and 41 (5.8\%) had two tumors of different histologic types. In seven $(1.0 \%)$ dogs there were three tumors of different histologic types and in one $(0.1 \%)$ four histologically unrelated tumors were diagnosed, performing 761 tumors. Out of the total of 761 skin tumors found, 673 (88.4\%) were neoplastic and 88 (11.6\%) were non-neoplastic. The 15 more frequently found tumors, in decreasing order of frequency, were: mast cell tumor, squamous cell carcinoma, perianal adenoma, lipoma, trichoblastoma, perianal carcinoma, papilloma, follicular cysts, hemangioma, hemangiosarcoma, melanoma, sebaceous adenoma, histiocytoma, nodular sebaceous hyperplasia and fibroma.

Key words: diseases of dogs, skin diseases, skin tumors, oncology, dermatology, pathology, dermatopathology.

\section{INTRODUÇÃO}

Dentre as especialidades veterinárias que atualmente se destacam, estão a dermatologia (SCOTT et al., 2001) e a oncologia (MacEWEN, 2001). Acreditase que, hoje, entre $20 \%$ e $75 \%$ dos atendimentos veterinários realizados em clínicas e hospitais estejam relacionados com problemas dermatológicos (SCOTT et al., 2001). Isso se deve principalmente ao fato de que alterações de pele chamam a atenção dos proprietários e causam repulsa, fazendo com que se procure auxílio veterinário (CONCEIÇÃO et al., 2004). Em um estudo realizado em 17 hospitais veterinários norteamericanos, os tumores de pele foram a segunda condição dermatológica mais diagnosticada, atrás apenas da hipersensibilidade à picada de pulga (SISCHO et al., 1989).

${ }^{1}$ Programa de Pós-graduação em Medicina Veterinária, área de concentração em Patologia Veterinária, Universidade Federal de Santa Maria (UFSM), 97105-900, Santa Maria, RS, Brasil. E-mail: teitsouza@yahoo.com.br. Autor para correspondência(Souza). ${ }^{2}$ Laboratório de Patologia Veterinária, Departamento de Patologia, UFSM, Santa Maria, RS, Brasil. 
A variedade de tumores de pele descrita em cães é bastante grande (PULLEY \& STANNARD, 1990; GOLDSCHMIDT \& SHOFER, 1992; GROSS et al., 1992; YAGER \& SCOTT, 1993; YAGER \& WILCOCK, 1994; SCOTT et al., 2001; GOLDSCHMIDT \& HENDRICK, 2002), o que dificulta os clínicos de pequenos animais conhecerem todas essas condições. Além disso, a falta de dados referentes à prevalência de cada um desses tumores na região de abrangência do Laboratório de Patologia Veterinária da Universidade Federal de Santa Maria (LPV-UFSM) torna difícil sua suspeita clínica com base nesse parâmetro diagnóstico. Dessa forma, considera-se oportuno determinar a prevalência dos tumores de pele que acometem os cães da região Central do Rio Grande do Sul e, assim, auxiliar os médicos veterinários locais no diagnóstico dessas condições tão rotineiras.

\section{MATERIAL E MÉTODOS}

Foram revisados todos os protocolos de biópsia de pele, arquivados no LPV-UFSM, entre janeiro de 1964 e dezembro de 2003 (40 anos), referentes aos cães dos municípios da região Central do RS. Dos protocolos de cães que apresentavam tumores cutâneos, foram retiradas as seguintes informações: diagnóstico morfológico, localização anatômica dos tumores, sexo e idade. Foram considerados sob a expressão "tumores cutâneos" todos os distúrbios do crescimento da pele, ou seja, tanto as neoplasias quanto os processos não-neoplásicos, como as hiperplasias nodulares, os nevos e os cistos.

Em todos os casos, foram considerados os diagnósticos morfológicos que constavam dos protocolos originais, isto é, não se procurou revisar os aspectos macroscópicos ou histológicos das lesões, nem foram aplicadas colorações especiais ou métodos de imunoistoquímica. Os tumores foram classificados em grupos de acordo com os principais livros de dermatologia (SCOTT et al., 2001), dermatopatologia (GROSS et al., 1992; YAGER \& WILCOCK, 1994), patologia (YAGER \& SCOTT, 1993; HARGIS, 1998; JONES et al., 2000) e oncologia (PULLEY \& STANNARD, 1990; GOLDSCHMIDT \& SHOFER, 1992; GOLDSCHMIDT \& HENDRICK, 2002) veterinária. Após essa classificação, foi calculada a prevalência de cada condição em relação ao total de tumores diagnosticados. Foram, também, registrados os tumores mais freqüentes quanto à faixa etária e à localização anatômica.

Para a classificação da localização anatômica foi utilizada a metodologia do principal levantamento sobre tumores de pele de cães existente na literatura
(GOLDSCHMIDT \& SHOFER, 1992). Dessa forma, os sítios anatômicos foram separados em: cabeça, pescoço, membro anterior, membro posterior, tórax, dorso, abdômen, períneo, cauda e escroto. Quando mais de um tumor de mesma classificação histológica ocorreu em diferentes localizações anatômicas de um mesmo cão, ele foi considerado como um subgrupo separado e denominado multicêntrico. Os cães que apresentavam mais de um tumor, mas, histologicamente diferentes (tumores múltiplos), foram incluídos no levantamento mais de uma vez, dentro de cada entidade específica. Dessa forma, há um maior número de tumores do que de cães.

As faixas etárias dos cães foram consideradas como segue: filhotes (até um ano de idade), adultos (de um a oito anos de idade) e idosos (acima de oito anos de idade). Os limites de cada faixa etária foram estipulados por consenso entre um grupo de clínicos de pequenos animais da região de abrangência do LPV-UFSM. Quanto ao sexo, os cães foram classificados apenas como macho ou fêmea, independentemente de serem castrados ou inteiros.

A raça dos cães não foi computada nesse estudo, pois nas décadas de 1960 e 1970 muitos protocolos omitiam esse parâmetro. Além disso, outro fato de difícil interpretação refere-se às cruzas, que podem tanto ser interpretadas como dentro da raça com características mais semelhantes ou como cães sem raça definida.

\section{RESULTADOS E DISCUSSÃO}

Nos arquivos do LPV-UFSM, que compreendem o período entre janeiro de 1964 e dezembro de 2003 (40 anos), foram encontrados 703 protocolos de biópsia de cães que apresentavam tumores cutâneos. Esses 703 protocolos estavam distribuídos em intervalos da seguinte maneira: 25 (1964-1973), 48(1974-1983), 161(1984-1993) e 469(19942003). Desses, em 36 (5,1\%) o sexo não foi informado. Dos 667 cães que tinham o sexo descrito nos protocolos, 377 (56,5\%) eram machos e 290 (43,5\%) eram fêmeas, ou seja, uma relação macho:fêmea de 1,3. Do total de 703 cães, 44 (6,2\%) não tiveram suas idades anotadas nos protocolos. Dos 659 cães em que a idade foi informada, 30 (4,5\%) foram incluídos como filhotes, 260 (39,5\%) como adultos e 369 (56,0\%) como idosos.

Nos 703 protocolos encontrados, em 578 $(82,2 \%)$ estava descrito que o cão apresentava apenas um tumor na pele e, em 125 (17,8\%), que o cão tinha mais de um tumor. Seiscentos e cinqüenta e quatro $(93,1 \%)$ cães tinham apenas um tipo histológico de tumor e 41 (5,8\%) apresentavam dois tumores 
histologicamente distintos. Em sete (1,0\%) cães havia três tumores diferentes e em um $(0,1 \%)$ cão foi diagnosticado quatro tumores não-relacionados, totalizando 761 tumores. Adicionalmente, dos 654 cães que tinham apenas um tipo histológico de tumor, 76 (11,6\%) demonstraram uma apresentação multicêntrica com dois a nove tumores idênticos distribuídos em locais diferentes da pele. Dos 41 e dos sete cães que apresentaram dois e três tipos distintos de tumor, sete (17,1\%) e um (14,3\%), respectivamente, demonstraram uma apresentação multicêntrica de um dos tipos histológicos.

Quanto à localização anatômica, 693 (91,1\%) dos 761 tumores encontrados tiveram sua distribuição informada, na seguinte ordem decrescente de freqüência: 108 (15,6\%) na cabeça, 96 (13,8\%) no abdômen, 88 (12,7\%) no membro posterior, 67 (9,7\%) no períneo, 66 (9,5\%) no tórax, 60 (8,6\%) no membro anterior, 44 (6,3\%) no pescoço, 36 (5,2\%) no dorso, 31 $(4,5 \%)$ no escroto e $13(1,9 \%)$ na cauda. Tumores multicêntricos foram encontrados em 84 (12,1\%) casos.

Do total de 761 tumores cutâneos encontrados, 673 (88,4\%) eram neoplásicos e 88 (11,6\%) não-neoplásicos. Dentre os 673 tumores neoplásicos descritos, 294 (43,7\%) eram epiteliais, 344 (51,1\%) mesenquimais e 35 (5,2\%) melanocíticos. Dos 294 tumores epiteliais, 171 (58,2\%) eram benignos e 123 (41,8\%) malignos. Dos 344 tumores mesenquimais, 133 (38,7\%) eram benignos e 211 (61,3\%) malignos. Dos 35 tumores melanocíticos, 10 (28,6\%) eram benignos e 25 $(71,4 \%)$ malignos. Dessa forma, do total de 761 tumores cutâneos encontrados nesse levantamento, 402 (52,8\%) eram proliferações benignas e 359 (47,2\%) malignas. A prevalência dos 761 tumores encontrados em ordem decrescente de freqüência pode ser observada na tabela 1 .

Quanto à localização, os tumores mais prevalentes na cabeça foram o tricoblastoma, o papiloma, o melanoma e o mastocitoma. No pescoço, os tumores mais encontrados foram o mastocitoma e o tricoblastoma. No membro anterior, o mastocitoma e o carcinoma de células escamosas foram os tumores mais prevalentes. No membro posterior, os principais diagnósticos incluíam mastocitoma e lipoma. Os tumores mais comumente encontrados no tórax foram o lipoma, o mastocitoma e o hemangioma. No abdômen, o mastocitoma, o carcinoma de células escamosas e o hemangiossarcoma foram os mais freqüentes. No dorso, houve predisposição para o tricoepitelioma e o mastocitoma, no períneo para o adenoma e o carcinoma perianal. No escroto, o mastocitoma constituiu quase a totalidade dos tumores. Na cauda, o adenoma perianal foi o tumor mais encontrado. O tumor mais freqüentemente visto na forma multicêntrica foi o mastocitoma.
Tabela 1 - Estudo retrospectivo de 761 tumores cutâneos em cães. Número absoluto e percentagem dos tumores cutâneos neoplásicos e não-neoplásicos.

\begin{tabular}{|c|c|c|}
\hline Tumores & $\begin{array}{l}\text { Número } \\
\text { absoluto }\end{array}$ & Percentagem \\
\hline Mastocitoma & 158 & 20,9 \\
\hline $\begin{array}{l}\text { Carcinoma de células } \\
\text { escamosas }\end{array}$ & 53 & 7,0 \\
\hline Adenoma perianal & 44 & 5,8 \\
\hline Lipoma & 42 & 5,5 \\
\hline Tricoblastoma & 35 & 4,6 \\
\hline Carcinoma perianal & 32 & 4,2 \\
\hline Papiloma & 30 & 3,9 \\
\hline Cistos foliculares & 28 & 3,7 \\
\hline Hemangioma & 25 & 3,3 \\
\hline Hemangiossarcoma & 25 & 3,3 \\
\hline Melanoma & 25 & 3,3 \\
\hline Adenoma sebáceo & 24 & 3,2 \\
\hline Histiocitoma & 20 & 2,6 \\
\hline Hiperplasia sebácea nodular & 19 & 2,5 \\
\hline Fibroma & 17 & 2,2 \\
\hline Carcinoma de células basais & 15 & 2,0 \\
\hline Hemangiopericitoma & 14 & 1,8 \\
\hline Carcinoma apócrino & 13 & 1,7 \\
\hline Tricoepitelioma & 12 & 1,6 \\
\hline $\begin{array}{l}\text { Acantoma } \\
\text { infundibular }\end{array}$ & 11 & 1,4 \\
\hline Calcinose circunscrita & 11 & 1,4 \\
\hline Fibrossarcoma & 10 & 1,3 \\
\hline Melanocitoma & 10 & 1,3 \\
\hline Nevo colágeno & 9 & 1,2 \\
\hline Carcinoma sebáceo & 7 & 0,9 \\
\hline Adenoma apócrino & 5 & 0,7 \\
\hline Cisto apócrino & 5 & 0,7 \\
\hline Cisto dermóide & 5 & 0,7 \\
\hline Lipoma infiltrativo & 5 & 0,7 \\
\hline Lipossarcoma & 5 & 0,7 \\
\hline Pilomatricoma & 5 & 0,7 \\
\hline Adenoma ceruminoso & 4 & 0,5 \\
\hline Mixossarcoma & 4 & 0,5 \\
\hline Nevo organóide & 4 & 0,5 \\
\hline $\begin{array}{l}\text { Tumor benigno de bainha de } \\
\text { nervo periférico }\end{array}$ & 4 & 0,5 \\
\hline Tumor venéreo transmissível & 4 & 0,5 \\
\hline Carcinoma basoescamoso & 3 & 0,4 \\
\hline Histiocitoma fibroso maligno & 2 & 0,3 \\
\hline Leiomioma & 2 & 0,3 \\
\hline Nevo vascular & 2 & 0,3 \\
\hline Plasmocitoma & 2 & 0,3 \\
\hline Adenoma meibomiano & 1 & 0,1 \\
\hline Corno cutâneo & 1 & 0,1 \\
\hline Dermatofibrose nodular & 1 & 0,1 \\
\hline Fasciíte nodular & 1 & 0,1 \\
\hline Linfoma epidermotrópico & 1 & 0,1 \\
\hline Linfoma não-epidermotrópico & 1 & 0,1 \\
\hline Mixoma & 1 & 0,1 \\
\hline Nevo apócrino & 1 & 0,1 \\
\hline Pólipo fibrovascular & 1 & 0,1 \\
\hline Queratose seborréica & 1 & 0,1 \\
\hline $\begin{array}{l}\text { Tumor maligno de bainha de } \\
\text { nervo periférico }\end{array}$ & 1 & 0,1 \\
\hline Total & 761 & 100 \\
\hline
\end{tabular}

Quanto à faixa etária, os tumores mais comumente vistos em filhotes foram o papiloma e o histiocitoma. Em cães adultos, o mastocitoma, o 
tricoblastoma e o carcinoma de células escamosas foram os mais prevalentes. Nos idosos, houve um maior número de mastocitomas, carcinomas de células escamosas e neoplasias perianais.

A realização de estudos retrospectivos quanto à prevalência de uma doença ou de um grupo de doenças relacionado a um determinado sistema orgânico é importante na patologia veterinária e na medicina veterinária como um todo. A partir desse tipo de pesquisa, é possível agrupar dados clínicos e laboratoriais sobre determinadas entidades clínicas; definir a prevalência de uma condição segundo a espécie, o sexo, a raça, a idade ou o estilo de vida; e desmitificar afirmações falaciosas sobre certas enfermidades, sinal clínico ou resultado de exame laboratorial, que, com o passar do tempo, acabam ganhando notoriedade.

A oncologia é hoje uma das especialidades que mais evolui dentro da medicina veterinária, prova disso é o grande número de livros, artigos científicos e eventos realizados na última década. Informações detalhadas sobre os diferentes tipos de tumores, no que se refere à patogênese, à epidemiologia, aos achados clínicos e laboratoriais, são assuntos de muitos livros e periódicos.

Dentro da oncologia, os tumores de pele são, sem dúvida, os mais estudados (GOLDSCHMIDT \& SHOFER, 1992). Isso ocorre principalmente porque esse tipo de alteração é facilmente notado pelos proprietários e, assim, os cães são encaminhados ao atendimento veterinário (GROSS et al., 1992). O maior estudo epidemiológico já realizado sobre tumores em cães e gatos foi conduzido de 1963 a 1967 nos condados de Alameda e Contra Costa na Califórnia (DORN et al., 1968a; DORN et al., 1968b). Nesse levantamento, realizado em uma população conhecida de cães e gatos, foram encontrados 1.077 casos de tumores em cães e 188 em gatos, para cada 100.000 animais/ano (DORN et al., 1968a; DORN et al., 1968b). Os tumores de pele corresponderam a 67,6\% e 44,8\% de todos os tumores diagnosticados nessas espécies, respectivamente (DORN et al., 1968a; DORN et al., 1968b). Em outro estudo, realizado no estado norteamericano de Oklahoma, a prevalência de tumores em cães e gatos foi de 1.126 e 470 novos casos/100.000/ ano, respectivamente (MacVEAN et al., 1978).

Estudos retrospectivos que incluam apenas tumores cutâneos em cães e gatos são freqüentes em vários locais do mundo, mas nenhum tinha sido ainda realizado no Brasil. Os quatro mais importantes levantamentos que traçaram a prevalência de cada um dos tumores de pele de cães foram feitos nos Estados Unidos (GOLDSCHMIDT \& SHOFER, 1992), no
Canadá (YAGER \& WILCOCK, 1994), no Reino Unido (BOSTOCK, 1977) e na Austrália (FINNIE \& BOSTOCK, 1979) e utilizaram um total de 29.150, 4.800, 2.616 e 1.000 tumores, respectivamente.

O presente estudo retrospectivo descreve 761 tumores encontrados em 703 cães num período de 40 anos, entre 1964 e 2003. Embora esse número de tumores seja inferior àqueles utilizados em outros levantamentos (BOSTOCK, 1977; FINNIE \& BOSTOCK, 1979; GOLDSCHMIDT \& SHOFER, 1992; YAGER \& WILCOCK, 1994), na região de abrangência do LPV-UFSM ele pode ser considerado substancial. Os resultados encontrados nesse estudo mostraram que a quantidade de tumores de pele de cães enviados a esse serviço de diagnóstico aumentou, de forma gradativa, aproximadamente 19 vezes entre os anos de 1964 e 2003. Isso parece ser fruto de mudanças na mentalidade dos proprietários e clínicos da região Central do Rio Grande do Sul.

Atualmente, a maneira pela qual os proprietários consideram um animal de estimação é muito diferente do que ocorria no passado. Dessa forma, a preocupação da população com a saúde e o bem estar de seus cães fez com que houvesse um aumento significativo na quantidade de atendimentos clínicos e cirúrgicos no Hospital de Clínicas Veterinárias da Universidade Federal de Santa Maria (HCV-UFSM). Em razão disso, maior procura pelos exames anátomohistopatológicos foi demonstrada pelos dados desse levantamento. Isso indica que, atualmente, os proprietários autorizam com mais facilidade os clínicos e os cirurgiões a enviarem os tumores de pele extirpados de seus cães para avaliação histológica. Além disso, o acesso facilitado à informação, pelo uso das redes de comunicação e por meio de publicações recentes na área da dermatologia e da dermatopatologia (GOLDSCHMIDT \& SHOFER, 1992; GROSS et al., 1992; YAGER \& WILCOCK, 1994; WILKINSON \& HARVEY, 1996; SCOTT et al., 2001; MEDLEAU \& HNILICA, 2003), permitiu que, nos últimos anos, os clínicos se conscientizassem da importância da análise anátomohistopatológica dos tumores cutâneos. A prova disso é que tem ocorrido um aumento significativo no envio de amostras referentes a tumores de pele por parte das clínicas veterinárias particulares, o que até pouco tempo era feito quase que exclusivamente pelo HCV-UFSM.

Outro dado interessante observado neste estudo é a quantidade de tumores encontrados em um mesmo cão. Dos 703 cães desse levantamento, 654 tinham apenas um tipo histológico de tumor, enquanto 41, sete e um tinham, dois, três e quatro tumores distintos, respectivamente. Além disso, dentro dos 654 cães com apenas um tipo histológico de tumor, 76 
tinham uma apresentação multicêntrica. Portanto, 578 cães apresentavam um tumor solitário e 125 cães tinham mais de um tumor, independente de ele ser histologicamente igual ou diferente, ou seja, é 4,6 vezes mais comum um cão ter apenas um tumor de pele solitário do que mais de um. Além disso, considerando essa apresentação em diferentes sítios anatômicos, foi 1,5 vezes mais comum eles serem histologicamente iguais do que diferentes. Dessa forma, embora seja muito mais freqüente um cão desenvolver apenas um tumor cutâneo solitário, em quase um quinto dos casos o clínico poderá se deparar com uma apresentação múltipla. Isso é importante porque, nesses casos, baseado nos resultados encontrados neste levantamento, o clínico deverá estar ciente que a chance desses tumores serem do mesmo tipo histológico é muito grande, mas isso não permite que apenas um dos tumores seja enviado para análise.

Os resultados encontrados referentes à localização anatômica mostram que, em cães, a cabeça é o local mais acometido por tumores de pele. Isso se deve ao fato de que quatro dos 12 tumores mais prevalentes nessa espécie, tricoblastoma, papiloma, adenoma sebáceo e melanoma, ocorreram preferencialmente na cabeça. Dos 761 tumores cutâneos encontrados nos 703 cães deste levantamento, 673 eram neoplásicos e 88 não-neoplásicos, o que demonstra que as neoplasias são 7,6 vezes mais comuns do que as lesões semelhantes à neoplasia. Esses valores são muito semelhantes aos descritos em outros levantamentos (BOSTOCK, 1977; FINNIE \& BOSTOCK, 1979; GOLDSCHMIDT \& SHOFER, 1992; YAGER \& WILCOCK, 1994). No maior desses estudos, que utilizou 29.150 casos, os tumores neoplásicos corresponderam a 25.943 e os não-neoplásicos a 3.207, ou seja, uma relação de 8,1 (GOLDSCHMIDT \& SHOFER, 1992). É fundamentalmente importante que os veterinários saibam da prevalência dos tumores cutâneos não-neoplásicos, a fim de que não encarem clinicamente toda e qualquer lesão proliferativa da pele como uma neoplasia.

Dentre o total de tumores cutâneos neoplásicos encontrados neste levantamento, os de origem mesenquimal foram 1,2 e 9,8 vezes mais comuns do que os epiteliais e os melanocíticos, respectivamente. Além disso, tumores epiteliais foram 8,4 vezes mais comuns que tumores melanocíticos. Esses resultados foram semelhantes aos descritos em três estudos (BOSTOCK, 1977; FINNIE \& BOSTOCK, 1979; YAGER \& WILCOCK, 1994) e quase idênticos aos encontrados em outro (GOLDSCHMIDT \& SHOFER, 1992). A explicação encontrada por nós para esse fato baseia-se nas seguintes premissas: 1) foi diagnosticada uma maior variedade de neoplasias mesenquimais do que epiteliais e 2) o mastocitoma, um tumor mesenquimal, correspondeu a $20,9 \%$ de todos os tumores.

Os achados referentes ao comportamento dos tumores avaliados neste estudo mostraram que a chance de um determinado tumor ser benigno ou maligno é virtualmente a mesma. Entretanto, quando esses tumores foram distribuídos em grupos quanto a sua origem, os resultados foram bastante diferentes: 1) os tumores melanocíticos foram 2,5 vezes mais malignos, 2) nas neoplasias mesenquimais a freqüência de malignidade foi 1,6 vezes maior e 3 ) os tumores de origem epitelial foram aproximadamente 1,4 vezes mais benignos. Esses resultados diferem grandemente dos encontrados em outros levantamentos (BOSTOCK, 1977; FINNIE \& BOSTOCK, 1979; GOLDSCHMIDT \& SHOFER, 1992; YAGER \& WILCOCK, 1994). Por exemplo, em um grande estudo de 29.150 casos, os tumores de origem epitelial, mesenquimal e melanocítica foram benignos em $85 \%$, 57\% e $81 \%$ dos casos, respectivamente (GOLDSCHMIDT \& SHOFER, 1992).

Há duas explicações para a alta proporção de tumores malignos neste estudo. A primeira e menos provável delas se refere a uma maior probabilidade dos tumores cutâneos que afetam os cães da região Central do Rio Grande do Sul serem, por algum motivo desconhecido, mais malignos do que os encontrados em outros locais do mundo. A segunda explicação refere-se a uma provável tendência em diagnosticar tumores cutâneos limítrofes ("border line”) como malignos. Nesses casos, a decisão entre malignidade e benignidade é, muitas vezes, feita com dificuldade, variando consideravelmente ou subjetivamente entre diferentes patologistas que examinam a mesma lesão. Há inclusive autores que se referem a patologistas "benignos" e malignos" nas suas interpretações de casos limítrofes (THOMSON, 1983).

\section{CONCLUSÕES}

Baseando-se nos achados deste estudo, pode-se concluir que o sítio anatômico mais prevalente quanto ao desenvolvimento de tumores cutâneos é a cabeça e que independentemente da localização eles são mais freqüentemente neoplásicos do que nãoneoplásicos. Além disso, dentre os tumores neoplásicos, os de origem mesenquimal são mais prevalentes do que os epiteliais, e esses mais freqüentes do que os melanocíticos. No geral, quando não se leva em consideração a faixa etária, o tumor cutâneo mais diagnosticado em cães na região Central do Rio Grande do Sul é o mastocitoma. 


\section{REFERÊNCIAS}

BOSTOCK, D.E. Neoplasia of the skin and mammary glands in dogs and cats. In: KIRK, R.W. Current veterinary therapy. Philadelphia: Saunders, 1977. p.493-505.

CONCEIÇÃO, L.G. et al. Biópsia e histopatologia da pele: um valioso recurso diagnóstico na dermatologia - revisão - parte 1. Clínica Veterinária, ano 9, p.36-44, 2004.

DORN, C.R. et al. Survey of animal neoplasms in Alameda and Contra Costa Counties, California. I. Methodology and description of cases. J Natl Cancer Inst, v.40, p.295-305, 1968a.

DORN, C.R. et al. Survey of animal neoplasms in Alameda and Contra Costa Counties, California. II. Cancer morbidity in dogs and cats from Alameda County. J Natl Cancer Inst, v.40, p.307-318, $1968 b$.

FINNIE, J.W.; BOSTOCK, D.E. Skin neoplasia in dogs. Australian Veterinary Journal, v.55, p.602-604, 1979.

GOLDSCHMIDT, M.H.; HENDRICK, M.J. Tumors of the skin and soft tissues. In: MEUTEN, D.J. Tumors in domestic animals. 4.ed. Ames: Iowa State, 2002. Cap.2, p.44-117.

GOLDSCHMIDT, M.H.; SHOFER, F.S. Skin tumors of the dog and cat. Oxford: Pergamon, 1992. 316p.

GROSS, T.L. et al. Veterinary dermatopathology: a macroscopic and microscopic evaluation of canine and feline skin disease. St. Louis: Mosby, 1992. 519p.

HARGIS, A.M. Sistema tegumentar. In: CARLTON, W.W.; McGAVIN, M.D. Patologia veterinária especial de Thomson. 2.ed. Porto Alegre : ARTMED, 1998. Cap.11, p.486-540.

JONES, T.C. et al. Patologia veterinária. 6.ed. São Paulo: Manole, 2000. 1415p.
MacEWEN, E.G. Tumors miscellaneous. In: WITHROW, S.J.; MacEWEN, E.G. Small animal clinical oncology. 3.ed. Philadephia: Saunders, 2001. Cap.29, p.639-646.

MacVEAN, D.W. et al. Frequency of canine and feline tumors in a defined population. Veterinary Pathology, v.15, p.700715, 1978.

MEDLEAU, L.; HNILICA, K.A. Dermatologia de pequenos animais - Atlas colorido e guia terapêutico. São Paulo: Roca, 2003. 353p.

PULLEY, L.T.; STANNARD, A.A. Tumors of the skin and soft tissues. In: MOULTON, J.E. Tumors in domestic animals. 3.ed. Berkeley : University of California, 1990. Cap.2, p.23-87.

SCOTT, D.W. et al. Muller \& Kirk - Dermatologia dos pequenos animais. 6.ed. Philadelphia: Saunders, 2001. 1528p.

SISCHO, W.M. et al. Regional distribution of 10 common skin diseases in dogs. Journal of American Veterinary Medicine Association, v.195, p.752-756, 1989.

THOMSON, R.G. Patologia geral veterinária. Rio de Janeiro: Guanabara Koogan, 1983. Cap.6, p.251-286.

WILKinson, G.T.; HARVEY, R.G. Atlas colorido de dermatologia dos pequenos animais: guia para o diagnóstico. 2.ed. São Paulo: Manole, 1996. 304p.

YAGER, J.A.; SCOTT, D.W. The skin and appendages. In: JUBB, K.V.F. et al. Pathology of domestic animals. 4.ed. San Diego: Academic, 1993. Cap.5, p.531-738.

YAGER, J.A.; WILCOCK, B.P. Color atlas and text of surgical pathology of the dog and cat: dermatopathology and skin tumors. London: Wolfe, 1994. Cap.3, p.239-313. 